\title{
TETRASOMY 15Q11-Q13 IDENTIFIED BY FLUORESCENCE IN SITU HYBRIDIZATION IN A PATIENT WITH AUTISTIC DISORDER
}

\author{
Ana Elizabete Silva', Sheila Adami Vayego-Lourenço², Agnes Cristina Fett-Conte ${ }^{3}$, \\ Eny Maria Goloni-Bertollo, Marileila Varella-Garcia4
}

\begin{abstract}
We report a female child with tetrasomy of the 15q11-q13 chromosomal region, and autistic disorder associated with mental retardation, developmental problems and behavioral disorders. Combining classical and molecular cytogenetic approaches by fluorescence in situ hybridization technique, the karyotype was demonstrated as 47,XX,+mar.ish $\operatorname{der}(15)(\mathrm{D} 15 \mathrm{Z1}++, \mathrm{D} 15 \mathrm{~S} 11++, \mathrm{GABRB} 3++, \mathrm{PML}-)$. Duplication of the $15 \mathrm{q}$ proximal segment represents the most consistent chromosomal abnormality reported in association with autism. The contribution of the GABA receptor subunit genes, and other genes mapped to this region, to the clinical symptoms of the disease is discussed.
\end{abstract}

KEY WORDS: tetrasomy 15, 15q11-q13, autism, fluorescence in situ hybridization, GABA receptors.

\begin{abstract}
Identificação de tetrassomia 15q11-q13 por hibridação in situ fluorescente em uma paciente com distúrbio autístico

RESUMO - Relatamos uma criança do sexo feminino com tetrassomia da região cromossômica 15q11q13 e distúrbio autístico associado com retardo mental, problemas de desenvolvimento e distúrbios comportamentais. A combinação de metodologias da citogenética clássica e molecular pela técnica de hibridação in situ fluorescente, demonstrou o cariótipo como 47,XX,+mar.ish der(15) (D15Z1++,D15S11++,GABRB3++,PML). Duplicação do segmento $15 q$ proximal representa a mais consistente anomalia cromossômica relatada em associação com autismo. A contribuição dos genes das subunidades do recepetor GABA, assim como outros genes mapeados nessa região, para os sintomas clínicos da doença é discutida.
\end{abstract}

PALAVRAS-CHAVE: tetrassomia 15, 15q11-q13, autismo, hibridação in situ fluorescente, receptores GABA.

Autism is a severe disorder that predominantly affects males ( 4 males: 1 female) $)^{1}$. The reported population prevalence ranges from 1 in $1,000^{2}$ to 1 in 10,000 live births ${ }^{1}$, this large range probably being due to inaccurate data collection based on Kanner's description of this syndrome. The diagnosis of autism is based upon a number of behavioral criteria including abnormal social behavior, language and cognitive development ${ }^{3}$. Similar to most behavioral syndromes, autism is etiologically heterogeneous and has been associated with a diverse set of infectious diseases such as rubella embryopathy and herpes encephalitis, or genetic conditions such as phenylke- tonuria, tuberous sclerosis, and fragile $X$ syndrome ${ }^{1 .}$ However, trisomy or tetrasomy of the 15q11-q13 region has also been reported in some autistic patients with varying degrees of mental retardation ${ }^{4-12}$. Abnormalities involving this chromosomal region are commonly identified in association to Prader-Willi syndrome (PWS) and Angelman syndrome (AS), usually as chromosomal deletion. Additional copies of this chromosomal segment are less frequently depicted and have been found in distinct phenotypes, including autistic disorder, a few PWS and AS cases $^{5,13}$, and even apparently normal individuals ${ }^{5,6,14}$.

This report describes a female patient with autis-

\footnotetext{
1Professor Assistente Doutor - Departamento de Biologia, IBILCE, State University of São Paulo (UNESP) Campus de São José do Rio Preto, SP, Brasil; ${ }^{2}$ Professor Assistente Doutor - Centro Universitário de Votuporanga, CEUV, Votuporanga, SP, Brasil; ${ }^{3}$ Professor Adjunto Departamento de Biologia Molecular, FAMERP, São José do Rio Preto, SP, Brasil; ${ }^{4}$ Associate Professor - Department of Medicine, University of Colorado Health Sciences Center, Denver, CO, USA. Financial support: Partially supported by grants from FUNDUNESP (Brazil) to AES, and the National Cancer Institute [CA46934] to MVG.
}

Recevied 8 Agust 2001, received in final form 26 October 2001. Accepted 5 November 2001. 
tic disorder whose karyotype displayed an extra chromosome, identified by the fluorescence in situ hybridization technique as a der(15) with a duplication of 15q11-q13. This case report reinforces the hypothesis that additional copies of this chromosomal segment may be causally related to autism.

\section{METHOD}

\section{Case}

The patient was a female, born at full term in 1988 by normal delivery, with a birth weight of $2,650 \mathrm{~g}$ and a body length of $46 \mathrm{~cm}$. The 29-year-old mother and the 30-yearold father were non-consanguineous and reported a previous first trimester spontaneous abortion. At 4 years of age, the patient presented with developmental delay, mental retardation, hyperactivity, poor motor coordination, stereotyped movements, anti-social behavior, abnormal language skills, and inability to maintain social approaches. She was diagnosed as having infantile autism $(\mathrm{DSM}-\mathrm{IIIR})^{15}$, and a multiprofessional therapy was initiated which resulted in pronounced improvement in the clinical picture. Physical examination at 8 years of age revealed hyperlaxity of joints, hypotonia, dolichocephaly, promi- nent occiput, malformed auricles, bilateral epicanthal folds, downslanting palpebral fissures, strabismus, high-arched palate, micrognathia, kyphoscoliosis, pectus excavatum, and bilateral fifth finger clinodactyly. Brain tomography, $X$-ray, and nuclear magnetic resonance evaluations were all normal. At that time, the diagnosis of autistic disorder $(\mathrm{DSM}-\mathrm{IV})^{3}$ was established.

\section{Cytogenetic studies}

Peripheral blood lymphocytes from the patient and her parents were cultured using PHA stimulated procedure, harvested and GTG banded following standard protocols. To confirm the origin of the marker chromosome that was found, dual target, single color fluorescence in situ hybridization (FISH) assays were performed. Slides were washed $1 \mathrm{~min}$ in $70 \%$ acetic acid, rinsed in PBS, digested at $37^{\circ} \mathrm{C}$ in RNase $\mathrm{A}(100 \mu \mathrm{g} / \mathrm{ml}$ in $2 \times \mathrm{SSC})$ for one $\mathrm{h}$ and in pepsin $(0.01 \%$ in $0.01 \mathrm{M} \mathrm{HCl})$ for $5 \mathrm{~min}$. Slides were then fixed in formaldehyde ( $1 \%$ in PBS) at $37^{\circ} \mathrm{C}$ for $5 \mathrm{~min}$, washed in PBS, dehydrated in an ethanol series, and denatured in $70 \%$ formamide/2xSSC for 3 min at $72^{\circ} \mathrm{C}$.

Three sets of DNA probes manufactured by Oncor (Gaithersburg, MD) were used: (a) D15Z1; (b) D15S11 and PML; (c) GABRB3 and PML D15Z1 is centromeric, D15S11

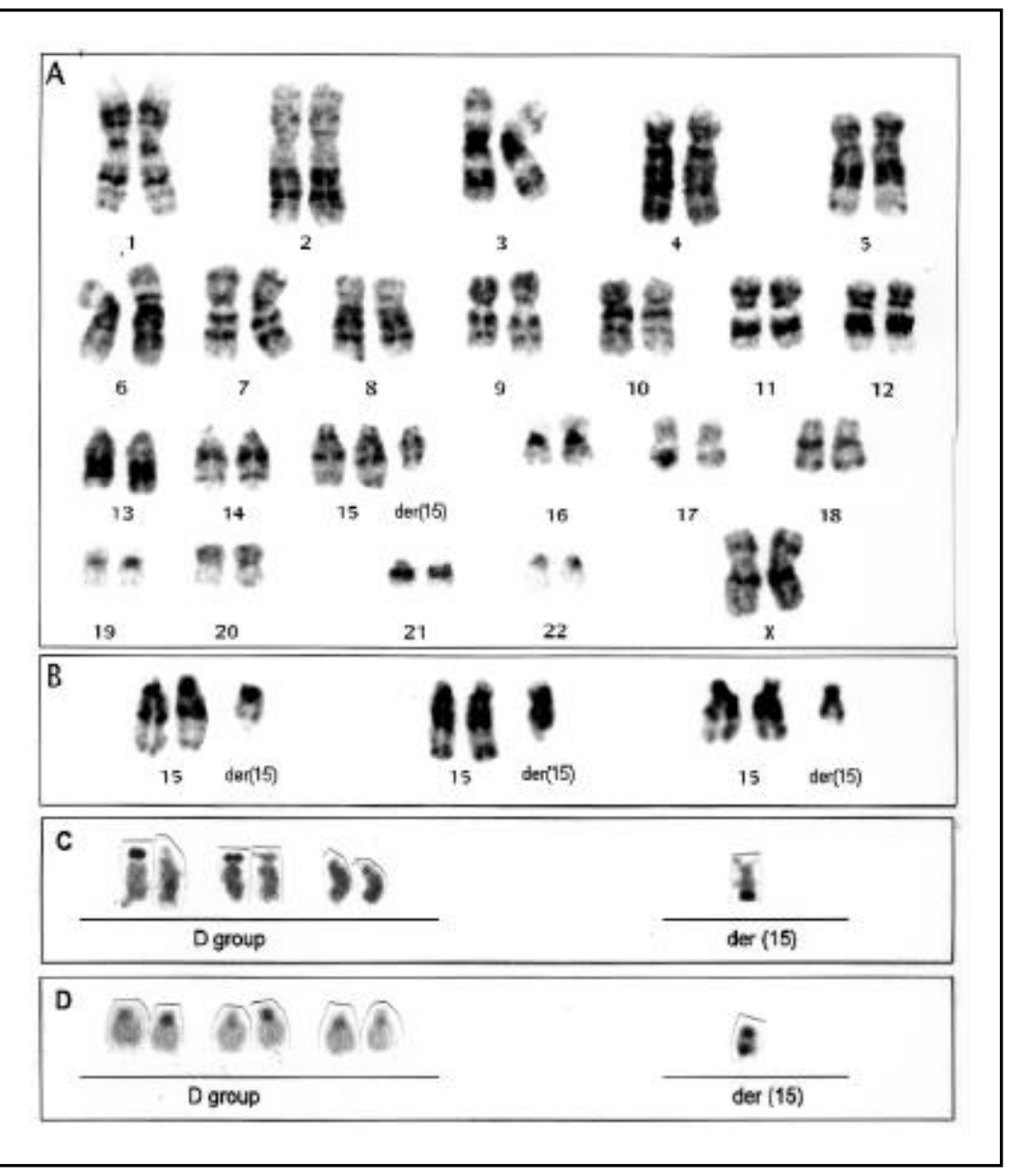

Fig 1. Complete (A) and partial (B) GTG-banding karyotypes. Partial karyotypes showing the $D$-group chromosomes: (C) AgNORbanding showing a single satellite extending from the long-arm end in the extra chromosome; (D) CBG-banding highlighting the functional centromere and an additional band at the end of the long arm of this extra chromosome. 


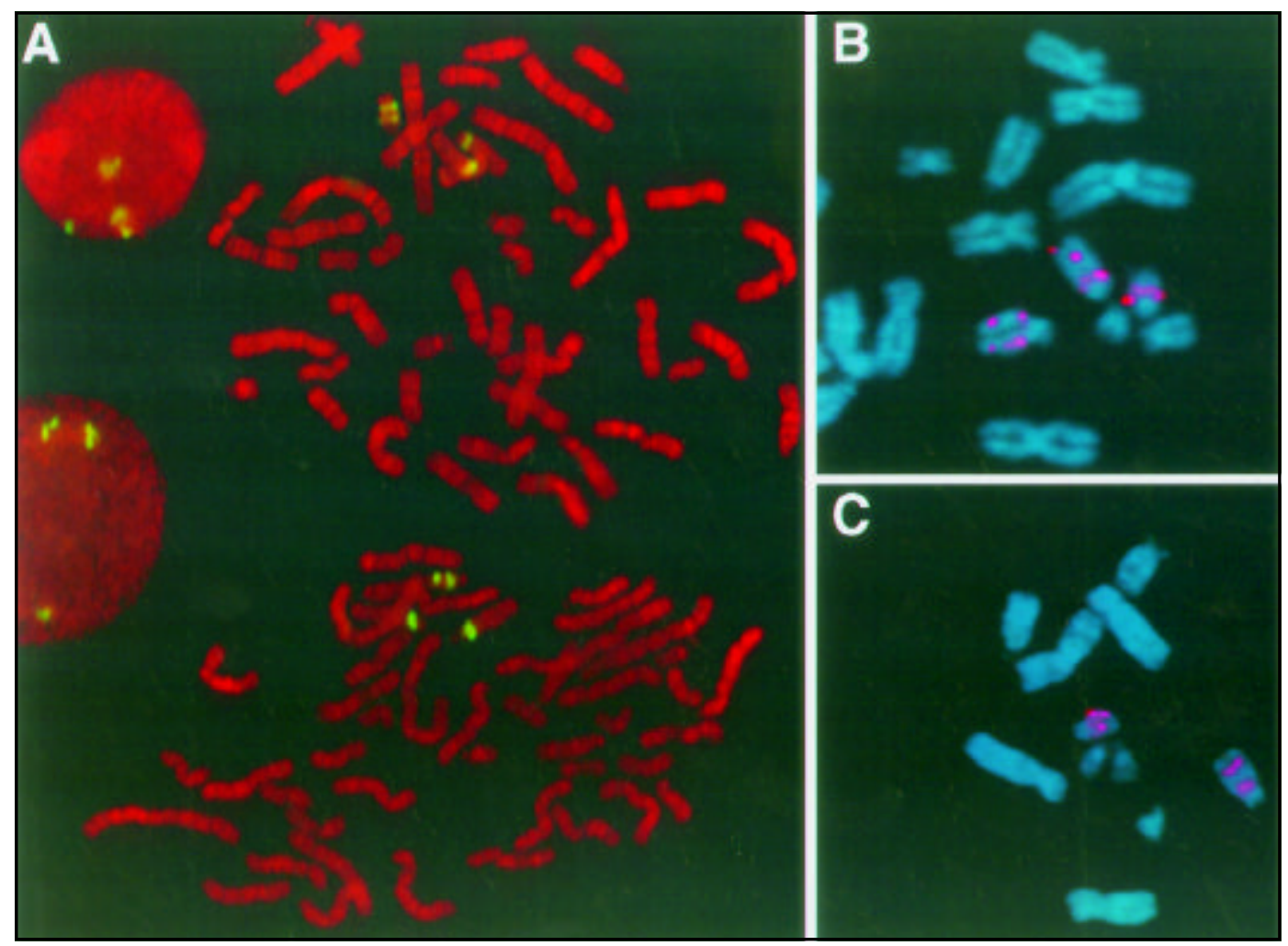

Fig 2. Metaphases hybridized with D15Z1 (A) and partial metaphases hybridized with D15S11/PML (B) and GABRB3 (C). Two normal copies of chromosome 15 displayed the expected centromeric signals and signals mapped at q11-13 and q21-22. The der(15) has two copies of the centromeric signal and a duplicated signal for D15S11 and GABRB3, suggesting tetrasomy 15q11-q13.

and GABRB3 are mapped at $15 q 11-q 13^{16}$, and PML is mapped at 15q21-22. All probes were labeled with digoxigenin, prepared following the manufacturer's instructions, and applied to selected areas of the slides. These areas were covered with glass coverslips, sealed with rubber cement and placed in a humidity chamber at $37^{\circ} \mathrm{C}$ where hybridization was allowed to occur for $20 \mathrm{~h}$, after which the slides were washed in $2 \times \mathrm{SSC}$ at $72^{\circ} \mathrm{C}$ for $5 \mathrm{~min}$. ProbeD15Z1 was detected with fluorescein isothiocyanate (FITC) and the two other probes with Rhodamine. Digoxigenin-Rhodamine detection was performed at $37^{\circ} \mathrm{C}$ using consecutive $30 \mathrm{~min}$ incubations in Rhodamine-sheep anti-digoxigenin, rabbit anti-sheep, and Rhodamine-anti-rabbit antibodies (Oncor's Digoxigenin-Rhodamine Detection Kit). Digoxigenin-FITC detection used FITC-avidin and biotinylated anti-avidin antibodies (Oncor Digoxigenin-FITC Detection Kit). Finally, slides were washed in PBS, dehydrated in an ethanol series, air dried, and counterstained with DAPI in Vectashield Mounting Medium (Vector Laboratories).

The slides were examined in an Olympus BX60 microscope using single interference filter sets of red (Texas red), green (FITC), blue (DAPI), dual (red/green), and triple (blue/ red/green) band-pass filters. For documentation, gray scale images for single color signals were captured using a cooled CCD camera (SenSys, Photometrics, Tucson, AZ), and were pseudocolored and merged using a Quips XL Genetics Workstation (Vysis, Inc.).

\section{RESULTS}

GTG-banding analysis of the patient's chromosomes revealed one small supernumerary chromosome in 20 cells scored, and the patient's karyotype was designated 47,XX,+mar (Figure 1A-B). This extra chromosome was acrocentric and, as was revealed by NOR-banding, showed satellites only at the ends of the long arm (Figure 1C). The CBG-banding highlighted the primary constriction plus an extra region at the end of the long arm, which appeared to be an inactive centromere (FigurelD). GTGbanding karyotypes of both parents were normal.

At least 30 metaphases were scored in each FISH assay and the results are illustrated in Figure 2. Preparations hybridized with probes D15Z1, D15S11/PML, and GABRB3/PML exhibited the expected signals in both copies of normal chromosome 15 . The extra chromosome was demonstrated to be der(15), and displayed a bright centromeric signal and a signal at the distal region of the long arm in both chromatids when hybridized with the D15Z1 probe (Fig 2A). This chromosome also exhibited two closely located fluorescent signals near the centromere in the hybridization assays with probes D15S11 (Fig 2B) and GABRB3, (Fig 2C), the signals being located in a faint 
DAPI band between the two centromeric signals, indicating that the der(15) chromosome has segment 15q11-q13 duplicated and that the karyotype of the patient is $47, \mathrm{XX},+$ mar.ish $\operatorname{der}(15)$ (D15Z1++, D15S11++,GABRB3++, PML-).

\section{DISCUSSION}

Although a variety of chromosomal anomalies have been described in individuals with autistic disorder $^{9,11,17}$, the occurrence of extra copies of 15q11q13 has been the one most frequently reported. Despite the great clinical variation amongst autistic patients with additional copies of the proximal region of $15 q$, our patient shared features such as mental retardation, hyperactivity, epicanthal folds, high-arched palate, kyphosis, and strabismus with another cases. Spontaneous abortion in the family, as observed in the present case, was also previously reported ${ }^{6,7}$. The number of additional copies of this region and the extent of the duplicated region are some of the major factors tentatively associated with clinical severity in these patients. In most cases, including the patient reported here, an inverted duplication [inv dup(15)(pter-q13)] in an additional chromosome was responsible for the tetrasomy of this region ${ }^{6,7,9,14}$. In a smaller number of cases this region was found in trisomy $y^{4,8,9}$. Trisomic patients usually displayed a milder phenotype while tetrasomic patients have more severe clinical features ${ }^{4,5,13,14}$.

A considerable heterogeneity in size, shape, and molecular composition of the $15 q$ proximal region was observed in the derivative chromosomes. Despite this, it is suggested that more severe features such as mental retardation and autistic behavior are associated with a longer extension of the duplication ${ }^{5,6}$. The der(15) found in the present patient is similar to the derivatives classified as type 3 in Cheng et al. ${ }^{5}$ and astype 1 in Crolla et al. ${ }^{6}$, which correspond to bi-satellited, dicentric marker with inv dup(15), including two additional copies of all loci extending from the centromere distal to D15S12, differing only in the presence of a single satellite at the end of the long arm.

Another factor that may play a role in the phenotypic variability reported in the literature is the parental origin of the extra chromosome. A large number of 15q11-q13 rearrangements of autistic patients which were evaluated for their parental origin were identified as maternally derived ${ }^{6,8,10,12,13}$. However, in this work is not possible to establish the parental origin of the extra chromosome. In a informative family, Cook et al. ${ }^{8}$ observed that paternally inherited duplications of 15q11-q13 led to a normal phenotype, whereas maternally inherited duplications led to typical or atypical autism. These findings suggest an important role for genetic imprinting in susceptibility to autism, which is not unexpected since the 15q11-q13 region is known to be critically imprinted in humans. Both paternal and maternal copies of this region are required for normal development, with loss of the paternal contribution leading to PWS and loss of the maternal contribution resulting in the AS phenotypes ${ }^{13}$. Surprisingly, Mohandas et al. ${ }^{18}$ reported a paternally derived de novo interstitial duplication of the proximal $15 q$ containing the PWS/AS critical region in a patient with developmental delay, which raises the question as to whether or not all paternal duplications are benign with respect to phenotype. Mohandas et al. ${ }^{18}$ hypothesized that the breakpoints generating the $15 q$ duplications, although clustered in the proximal $15 q$, may vary at the molecular level resulting in dosage changes for a different set of genes. It is also possible that the clinical findings in this patient may not be causally related to the duplication.

A number of genes potentially related to autism have been mapped at 15q11-q13. These genes include the pigmentation gene $P$, which is suggested to be related with the hypomelanosis of Ito ${ }^{19}$, the ubiquitin-protein ligase (UBE3A) that is responsible for $A S^{20}$, and the three $G A B A_{A}$ receptor subunits, GABRB3 $^{21}$, GABRA5 ${ }^{22}$ and GABRG ${ }^{23}$. GABA is the major inhibitory neurotransmitter in the mammalian brain with synaptically released GABA activating receptors which open chloride-permeable ion channels and inhibit the electrical activity of the neuron, thus making it less responsive to an excitatory input ${ }^{24}$. Previous studies indicated a role for GABA in the suppression of seizure activity and defects in GABA receptor function in the brain might be expected to produce seizures, uncontrolled behavior, and disorders of movement, all effects related with suppression of $\beta 3$ subunit gene expression ${ }^{21}$. Wagner et al. ${ }^{25}$ reported that GABA can also act as an excitatory transmitter and can excite mature neurons in the suprachiasmatic nucleus of the hypothalamus. It acts as an inhibitory neurotransmitter at night and an excitatory neurotransmitter during the day. This dual effect, which is mediated by GABA receptors, may be attributed to a diurnal oscillation in intracellular chloride concentration. Therefore, it is conceivable that an excess of GABA receptors could lead to 
behavioral problems such as hyperactivity and to epilepsy. Whether the GABA receptor gene is causally related to autism is not yet clear, and the duplicated chromosomal segment notably includes several other genes. However, Cook et al. ${ }^{26}$ screened nine loci on the 15q11-q13 region for linkage disequilibrium with autistic disorder, and linkage disequilibrium was found only affecting GABRB3 155CA-2 locus, pointing to this gene as a causative candidate gene for autistic disorder.

The currently available data underline the necessity of searching for chromosome 15q11-q13 abnormalities in patients with autism, and support the molecular analysis of this region as an approach to the clarifycation of the etiology of this disorder.

Acknowledgement - The authors acknowledge the technical support received from Josué Rodrigues dos Santos and Cintia Fridman.

\section{REFERENCES}

1. Jorde LB, Hasstedt SJ, Ritvo ER, et al. Complex segregation analysis of autism. Am J Hum Genet 1991;49:932-938.

2. Gillberg C, Wing L. Autism: not an extremely rare disorder. Acta Psychiatr Scand 1999; 99:399-406.

3. American Psychiatric Association. Diagnostic and statistical manual of mental disorders: fourth Ed. Washington, DC: American Psychiatric Association. 1994.

4. Baker P, Piven J, Schwartz S, Patil S. Brief report: duplication of chromosome 15q11-q13 in two individuals with autistic disorder. J Autism Dev Disord 1994;24: 529-535.

5. Cheng SD, Spinner NB, Zackal EH, Knoll JHM. Cytogenetic and molecular characterization of inverted duplicated chromosome 15 from 11 patients. Am J Hum Genet 1994;55:753-759.

6. Crolla JA, Harvey JF, Sitch FL. Supernumerary marker 15 chromosome: a clinical, molecular and FISH approach to diagnosis and prognosis. Hum Genet 1995;95:161-170.

7. Hotopf M, Bolton P. A case of autism associated with partial tetrasomy 15. J Autism Dev Disord 1995;25: 41-49.

8. Cook EH Jr, Lindgren V, Leventhal BL, et al. Autism or atypical autism in maternally but not paternally derived proximal 15q duplication. Am J Hum Genet 1997;60: 928-934.
9. Schroer RJ, Phelan MC, Micahelis RC, et al. Autism and maternally derived aberrations of chromosome 15. Am J Med Genet 1998;76:327-336.

10. Gurrieri F, Bataglia A, Torrisi L, et al. Pervasive developmental disorder and epilepsy due to maternally derived duplication of 15q11-q13. Neurology 1999;52:1694-1697.

11. Konstantareas MM, Homatidis S. Chromosomal abnormalities in a series of children with autistic disorder. J Autism Dev Disord 1999;29:275-285.

12. Wolpert CM, Menold MM, Bass MP, et al. Three probands with autistic disorder and isodicentric chromosome 15. Am J Med Genet 2000;96:365-372.

13. Robinson WP, Wagstaff J, Bernasconi F, et al. Uniparental disomy explains the occurrence of the Angelman or Prader-Willi syndrome in patients with an additional small inv dup(15) chromosome. Am J Med Genet 1993;30:756-760.

14. Leana-Cox J, Jenkins L, Palmer CG, et al. Molecular cytogenetic analysis of inv dup(15) chromosomes, using probes specific for the PraderWilli/Angelman syndrome region: clinical implications. Am J Hum Genet 1994;54:748-756.

15. American Psychiatric Association. Diagnostic and statical manual of mental disorders: third edition revised. Washington, DC.: American Psychiatric Association. 1987.

16. Malcon S, Donlon T. Report of the second international workshop on human chromosome 15 mapping 1994. Cytogenet Cell Genet 1994;67:214.

17. Li SY, Chen YCJ, Lat TJ, Hsu CY, Wang YC. Molecular and cytogenetic analysis of autism in Taiwan. Hum Genet 1993;92:441-445.

18. Mohandas TK, Park JP, Spellman RA, et al. Paternally derived de novo interstitial duplication of proximal $15 q$ in a patient with developmental delay. Am J Med Genet 1999;82:294-300.

19. Pellegrino JE, Schnur RE, Kline R, Zackai EH, Spinner NB. Mosaic loss of 15q11-q13 in a patient with hypomelanosis of ITO: is there a role for the P gene? Hum Genet 1995; 96:485-489.

20. Matsuura T, Sutcliffe JS, Fang P et al. De novo truncating mutations in E6-AP ubiquitin-protein ligase gene (UBE3A) in Angelman syndrome. Nat Genet 1997;15:74-77.

21. Wagstaff J, Knoll JHM, Fleming J et al. Localization of the gene encoding the $\mathrm{GABA}_{\mathrm{A}}$ receptor beta 3 subunit to the Angelman/Prader-Willi region of human chromosome 15. Am J Hum Genet 1991;49:330-337.

22. Glatt KA, Sinnett D, Lalande M. Dinucleotide repeat polymorphism at the $\mathrm{GABA}_{\mathrm{A}}$ receptor alpha-5 (GABRA5) locus at chromosome 15q11q13. Hum Mol Genet 1992;1:348.

23. Greger V, Knoll JHM, Woolf E, et al. The gamma-aminobutyric acid receptor gamma-3 subunit gene (GABRG3) is tightly linked to the alpha- 5 subunit gene (GABRA5) on human chromosome 15q11-q13, and is transcribed in the same orientation. Genomics 1995;26:258-264.

24. Cowell CS. Time to get excited by GABA. Nature 1997;387:554-555.

25. Wagner S, Castel M, Gainer H, Yaron Y. GABA in the mammalian suprachiasmatic nucleus and its role in diurnal rhythimicity. Nature 1997;387:598-603.

26. Cook EH Jr, Courchesne RY, Cox NJ, et al. Linkage-disequilibrium mapping of autistic disorder, with 15q11-13 markers. Am J Hum Genet 1998;62:1077-1083. 